\title{
1 Human inbreeding has decreased in time through the Holocene
}

\section{Authors}

3 Francisco C. Ceballos ${ }^{1+}$, Kanat Gürün ${ }^{1+}$, N. Ezgi Altınışık ${ }^{2}$, Hasan Can Gemici³ ${ }^{3}$, Cansu Karamurat ${ }^{3}$, Dilek

4 Koptekin ${ }^{1}$, Kıvılcım Başak Vural ${ }^{1}$, Elif Sürer ${ }^{4}$, Yılmaz Selim Erdal2 ${ }^{2}$, Anders Götherström,6, Füsun

5 Özer², Çiğdem Atakuman ${ }^{3}$, Mehmet Somel $^{1}$

$7 \quad$ these authors have contributed equally to the manuscript

9 Affiliations

10 1Department of Biological Sciences, Middle East Technical University, 06800, Ankara, Turkey

11 2Human-G Laboratory, Department of Anthropology, Hacettepe University, 06800, Ankara, Turkey

12 32Department of Settlement Archaeology, Middle East Technical University, 06800, Ankara, Turkey

13 4Department of Modeling and Simulation, Graduate School of Informatics, Middle East Technical

14 University, 06800, Ankara, Turkey

15 5Department of Archaeology and Classical Studies, Stockholm University, Stockholm, Sweden

$16{ }^{6}$ Centre for Palaeogenetics, Svante Arrhenius väg 20C, SE-106 91 Stockholm

\section{Highlights}

20 A study of 440 ancient genomes shows inbreeding decreased over time.

21 The decrease appears linked with population size increase due to farming.

22 Extreme consanguineous matings did occur among farmers, but rarely. 


\section{Summary}

2 The history of human inbreeding is controversial. The development of sedentary agricultural

3 societies may have had opposite influences on inbreeding levels. On the one hand, agriculture and

4 food surplus may have diminished inbreeding by increasing population sizes and lowering

5 endogamy, i.e. inbreeding due to population isolation. On the other hand, increased sedentism, as

6 well as the advent of private property may have promoted inbreeding through the emergence of

7 consanguineous marriage customs or via ethnic and caste endogamy. The net impact is unknown,

8 and to date, no systematic study on the temporal frequency of inbreeding in human societies has been

9 conducted. Here we present a new approach for reliable estimation of runs of homozygosity (ROH)

10 in genomes with $\geq 3 \mathrm{x}$ mean coverage across $>1$ million SNPs, and apply this to 440 ancient Eurasian

11 genomes from the last 15,000 years. We show that the frequency of inbreeding, as measured by ROH,

12 has decreased over time. The strongest effect is associated with the Neolithic transition, but the trend

13 has since continued, indicating a population size effect on inbreeding prevalence. We further show

14 that most inbreeding in our historical sample can be attributed to endogamy, although singular cases

15 of high consanguinity can also be found in the archaeogenomic record.

\section{Keywords}

18 Runs of homozygosity; inbreeding; consanguinity; endogamy; archaeogenomics 


\section{RESULTS AND DISCUSSION}

To study ROH levels in time, we tailored the PLINK implementation of ROH calling to suit low coverage ancient genomes. Simulations performed by downsampling 44 relatively high coverage ( $>10 \mathrm{x}$ ) ancient genomes revealed that the default PLINK algorithm overestimates the sum and number of ROH's at <4x coverage, due to missed heterozygous positions in the data (Table S1, Figure S1, Figure S2 A and C). We accounted for this effect using an empirical approach: depending on coverage, we vary the parameters of PLINK with respect to the number of heterozygous SNP allowed

8 per window (see Materials and Methods). With this approach we were able to estimate the number 9 and sum of $\mathrm{ROH}>1 \mathrm{Mb}$ reliably for $>3 \mathrm{x}$ coverage genomes in simulations (Figure S1 B and D). We further confirmed that $\mathrm{ROH}$ calls $>1 \mathrm{Mb}$ were free of the influence of coverage by studying the correlation between genome coverage and the sum or the number of $\mathrm{ROH}>1 \mathrm{Mb}$ across 440 ancient individuals with $\geq 3 \mathrm{x}$ mean SNP coverage across the $1240 \mathrm{~K}$ SNP set [1] (see Materials and Methods). Meanwhile, we discarded small ROH $(<1 \mathrm{Mb})$, as we found that these cannot be identified reliably with low coverage genomes using our approach (see Materials and Methods).

Our analyses below focus on the number and sum of $\mathrm{ROH}>1 \mathrm{Mb}$ estimated across these $\mathrm{n}=440$ published genomes using our empirical approach (Figure 1, Figure 2A), as well as among n=444 contemporary human individuals (Figure 2B). We focused on West Eurasia (Europe) and Central Eurasia (SW Asia, Caucasus, and Central Asia), regions with the highest published ancient genome data density. To study the effects of changing sociocultural organization through time, we separated past societies into four historical categories based on the degree of their social complexity: huntergatherers, who subsisted on the wild resources of the land within egalitarian mobile bands (e.g. Gravettian hunter-gatherers in Eastern Europe); simple agriculturalists, the earliest adopters of agriculture within relatively egalitarian sedentary communities (e.g. Linearbandkeramik farmers of Central Europe); early complex agriculturalists, farmer/pastoralist communities with an emerging institutionalized hierarchy and specialization (e.g. Bell Beaker groups known mainly from burials in West and Central Europe); and advanced complex agriculturalists, who lived in highly stratified societies organized around state systems (e.g. the Roman state in the Mediterranean).

\section{8}

\section{Temporal and spatial distribution of human inbreeding}

29 We first studied the temporal distribution of $F_{R O H}$, or genomic inbreeding levels. We find a manifest 30 trend of decreasing levels of inbreeding over time in West and Central Eurasia (Figure 1A). When 31 separating the data into five historical categories, from hunter-gatherers to advanced complex 
agriculturalists and finally to contemporary humans, we observe the same trend. Notably, the largest shift in $F_{R O H}$ occurs between hunter-gatherers and agriculturalists, during the Neolithic transition, but the trend is sustained in later periods. We find significant differences between almost every pair of historical categories but simple agriculturalists vs. early complex agriculturalists, and advanced complex agriculturalists vs. modern-day populations (Table S2).

We further analysed the data using a multiple regression model with $F_{R O H}$ as the dependent variable, and time (i.e. historical age) and historical category as independent variables. Time had a positive and significant effect $\left(\beta_{\text {Time }}=3.98 \mathrm{e}^{-06}, p=3.7 \mathrm{e}^{-06}\right)$, while the effect of the different historical categories was also significant in comparison to the baseline set by the hunter-gatherers (simple agriculturalists' effect $=-3.01 \mathrm{e}^{-02}, p<2.2 \mathrm{e}^{-16}$; early complex agriculturalists' effect $=-2.5 \mathrm{e}^{-02}, p=7.1 \mathrm{e}^{-}$ 08; advanced complex agriculturalists' effect $=-3.1 \mathrm{e}^{-02}, p=5.3 \mathrm{e}^{-07}$ and contemporary societies' effect $=-3.4 \mathrm{e}^{-02}, p=1.83 \mathrm{e}^{-05}$ ). This can also be observed in Figure 1B. Notably, contemporary populations have the lowest inbreeding levels, despite notable variability within this group (Table 1).

14 We next studied the spatial distribution of $F_{R O H}$. Notably, the distribution of $F_{R O H}$ is highly structured in present-day Eurasia (Figure S2 B). In contrast, we found that temporal changes in $F_{R O H}$ are largely consistent across different regions of Eurasia: neither a multiple regression analysis, with latitude and longitude as dependent variables $\left(\beta_{\text {latitude }}=1.9 \mathrm{e}^{-04}, p=0.213 ; \beta_{\text {longitude }}=9.7 \mathrm{e}^{-06}, p=0.77\right)$, nor kriging analysis (Figure 2) revealed any prominent spatial structure for $F_{R O H}$ through different historical categories.

\section{The origins of autozygosity in ancient humans}

Some ancient individuals show extreme autozygosity (i.e. homozygosity created by inbreeding) within our dataset (Figure 1A). We explored the origin of these signals, asking whether, in each case, consanguinity or endogamy (i.e. genetic isolation and strong genetic drift) could be the culprit. For this, we compared the number of ROH vs. the sum of ROH per individual genome using ROH >1.5 Mb [2]. In Figure 3, the diagonal line represents an outbred population; individuals with high values along the diagonal exhibit high autozygosity due to endogamy, while "right shifts" from the diagonal indicate consanguinity. We observe that inbreeding among our sample of 440 ancient individuals can be mostly attributed to endogamy, caused by low population size. Most notably, individuals assigned to the hunter-gatherer category, with overall high $F_{R O H}$ levels, revealed close to no indication of consanguinity. This included some West Eurasian hunter-gatherers with extreme levels of inbreeding $\left(F_{R O H}>0.125\right.$; Chan, I0015, Villabruna, R7 and I0410). The vast majority of later-coming 
agriculturalists also showed no evidence of consanguinity. Within the agriculturalist sample, however, the three individuals with the most extreme levels of inbreeding $\left(F_{R O H}>0.125\right)$ also showed clear signs of consanguinity. Based on simulations (see Materials and Methods), we estimate that

4 NG10 from Middle Neolithic (3338-3028 cal BCE) Ireland is the offspring of an incest mating, as 5 suggested by Cassidy and colleagues [3] (Figure 3b). We also estimate that I6671 from Early-Middle Bronze Age (3000-2039 cal BCE) Turkmenistan and I2521 from Neolithic (5619-5491 cal BCE) Bulgaria may be the offspring of avuncular matings, while also exhibiting additional autozygosity due to genetic drift.

9 We further studied the distribution of ROH using the total length of ROH values for different ROH track lengths (Figure 6). The size of ROH is inversely correlated with its age: longer ROH results from recent common ancestors, while shorter $\mathrm{ROH}$ come from distant ancestors, broken down by recombination. We found that among those hunter-gatherer individuals with extreme autozygosity created by genetic drift, total lengths of short ROH $(1 \mathrm{Mb}<\mathrm{ROH}<2 \mathrm{Mb})$ are high. Conversely, among the three most consanguineous individuals, NG10, I6671 and I2521, total lengths of long ROH (ROH> $8 \mathrm{Mb}$ ) are highest. The individual NG10 reveals $5 \mathrm{ROH}$ of size $>30 \mathrm{Mb}$, with an estimated age of just 1 generation [4].

17 Overall, we observe that consanguinity explains a small fraction of the overall autozygosity observed, with only $3(0.6 \%)$ of the total number of the ancient individuals analysed exhibiting clear evidence of high consanguinity.

\section{The origins of present-day homozygosity in Central Eurasia}

21 We then studied the spatial distribution of present-day inbreeding prevalence in relation to ancient inbreeding patterns. Figure 3D presents the average sum of the different ROH sizes across regions and historical categories. This reveals an interesting spatiotemporal structure, especially for the shorter ROH in Figure 3D. West Eurasian hunter-gatherers carry the highest total length of short ROH among all historical groups, attesting to their small population size around the early Holocene. However, this inbreeding signal is rapidly lost, and West Eurasian advanced agriculturalists carry the lowest average sum of short $\mathrm{ROH}$ among all ancient groups studied. In Central Eurasia, the total length of short ROH is also high in hunter-gatherers and decreases in later-coming periods, but at a more modest rate. Compared to ancient populations, present-day populations have the shortest average total length of shorter $\mathrm{ROH}$, denoting large effective population size and slow genetic drift. 
1 However, this temporal pattern vanishes when we study the total length of longer ROH, e.g. ROH

2 between 4 and $8 \mathrm{Mb}$. Importantly, $\mathrm{ROH}>4 \mathrm{Mb}$ may have an age of 5 to 10 generations [5-7] and thus

3 indicate relatively close consanguinity. Figure 3D shows that some modern Central Eurasian

4 populations (e.g. Balochi of Pakistan or the Bedouin from Saudi Arabia), reveal higher total lengths

5 of ROH between 4 and $8 \mathrm{Mb}$ than any other group in the HGDP, as well as any of our historical

6 categories.

7 In Table 1 we present comparisons of median $F_{R O H}$ and the frequency of inbred individuals. As also

8 observed in Figure 3, we find that contemporary populations tend to have the lowest proportions of 9 inbred individuals. However, some contemporary Eurasian populations have exceptionally high 10 proportions of individuals with $F_{R O H}>0.0391$ (i.e. individuals who could be offspring of first cousin 11 matings or closer matings, ignoring drift; Supplemental Information). This is especially salient among 12 certain Central Eurasian populations. Modern groups like the Balochi, the Bedouin, or the Sindhi from 13 Pakistan have the highest proportions of individuals with $F_{R O H}>0.0391$ (50\%, 41.3\% and 33.3\% 14 respectively).

15 Comparing contemporary Central vs. West Eurasia with respect to the proportion of inbred 16 individuals, we find a significant difference between the two regions, both for individuals with $F_{R O H}>$ 170.0391 (odds ratio $=13.5$, Fisher's exact test $p=9 \mathrm{e}^{-10}$ ) and also for individuals with $F_{R O H}>0.0117$ 18 (individuals who could be offspring of second cousin matings or closer matings, ignoring drift) (odds 19 ratio $=6.2, p=7 \mathrm{e}^{-14}$ ) (Table 1). Because Central Eurasian populations also exhibit relatively high total 20 lengths of long ROH, this excess of inbred individuals could be attributed to consanguinity, rather 21 than other processes such as caste endogamy, and is consistent with documented cultural 22 preferences for first-cousin matings in some contemporary societies [8,9].

23 This raises the question whether the differential rates of consanguinity among present-day Central 24 vs. West Eurasia could be traced back in time. In fact, we observed an excess of individuals with $F_{R O H}$ $25>0.0117$ in Central vs. West Eurasia among advanced complex agriculturalists (odds ratio $=5.1, p=$ 26 0.009; Table 1). However, we find no indication that this was driven by consanguinity (excess of long $27 \mathrm{ROH}$ ) in ancient societies (Figure 3), which suggests that the high consanguinity in this region 28 observed today might have only a recent history.

\section{CONCLUSION}

30 Our work shows that the Neolithic transition to agriculture and the emergence of complex societies 31 did not necessarily increase the overall levels of inbreeding among humans, at least in the case of 
1 West and Central Eurasia. On the contrary, the respite from endogamy via food production and

2 technology-driven increase in population size seem to have mitigated inbreeding levels throughout

3 recent history. Of course here we rely on the assumption that the 440 individuals analysed in this

4 study were representative of their time. Sampling biases caused by various factors, such as burial

5 location of the elite vs. the commoners, or a focus on elite burials by archaeologists, could influence

6 inferences on class-based societies. That said, as our data derive from 189 different archaeological

$7 \quad$ sites and also because we observe the continuation of the same temporal trend of lower inbreeding

8 in contemporaneous human groups, we consider our conclusions to be valid. We further note that

9 our results are in line with previous singular reports on ROH in archaic hominins and ancient Homo

10 sapiens individuals, which suggest high ROH was a common phenomenon in Paleolithic or early

11 Holocene hunter-gatherer groups. For instance, the genome of the 50,000-year-old Altai Neanderthal

12 individual revealed an inbreeding coefficient of $1 / 8$, equivalent to an offspring of avuncular mating

13 [10]. Genomes of foragers from Upper Paleolithic and Mesolithic periods from Europe and the

14 Caucasus also display evidence for inbreeding, mainly in the form of endogamy [11,12]. Endogamy

15 among hunter-gatherers may be expected, as it is commonly observed in wild $K$-selected species of

16 small population size, such as mammoths $[13,14]$.

17 Three points further deserve mention. One is the apparent contrast between relatively high levels of

18 endogamic inbreeding among ancient hunter-gatherer societies, and reports of low levels of

19 inbreeding among modern-day hunter-gatherers. Recent ethnographic studies have documented low

20 inbreeding in a world-wide sample of contemporary hunter-gatherers living in smaller groups,

21 compared to Amazonian horticulturalists living in larger groups [15]. Hill and colleagues also report

22 low levels of relatedness within and high interconnection among modern-day hunter-gatherer bands

23 [16]. This discrepancy could be attributed to various factors, such as reciprocal exogamy traditions

24 or larger population sizes among modern-day hunter-gatherers sampled in ethnographic studies

25 [17], which may vary from early Holocene European hunter-gatherers, which predominate our

26 sample. In the future, estimating endogamy in non-European hunter-gatherer groups of the last

2710,000 years would be crucial for resolving the prevalence of endogamy in pre-agricultural human

28 societies. The answer, in turn, could be vital for models of how human cooperation has evolved

$29[18,19]$.

30 Second, our data lend support, albeit weakly, to the hypothesis that extreme consanguinity may have

31 become more common with farming. This result is also consistent with singular reports on ancient

32 agriculturalist genomes, such as evidence for consanguinity identified in an early Neolithic farmer 
1 from Iran [20], a first-degree incest case from Neolithic Ireland [3], as well as a recent report on close-

2 kin unions in the central Andes after 1000 CE [21]. This is intriguing as we find overall lower levels

3 of inbreeding in agricultural than in hunter-gatherer societies, although the latter effect can be

4 attributed to lower endogamy, and not lower consanguinity. At the same time, among the 7 most

5 highly inbred individuals (with $F_{R O H}>0.125$ ), all 4 hunter-gatherers are mainly endogamous, while

6 all 3 agriculturalists are mainly consanguineous. This is an unlikely observation (Fisher's exact test

$7 \quad p=0.029$ ) and appears consistent with the notion that consanguineous traditions could have thrived

8 in class-based agricultural societies more readily than in more egalitarian hunter-gatherer groups

9 [15].

10 Finally, we find higher consanguinity in Central vs. West Eurasia in contemporary societies. This is

11 consistent with widespread cousin marriage practices in agricultural societies in Middle Eastern and

12 North African (MENA) countries and in South Asia, mostly among Muslim and Jewish groups, as

13 documented by ethnographic or genomic studies [8,22,23]. We note that cousin marriages were also

14 common among royal dynasties and upper classes of Europe until the 20th century, and many

15 prominent European scientists of that period are known to have married their first cousins, including

16 Charles Darwin and Albert Einstein [24,25]. These traditions are thought to have arisen through

17 various social factors, including the inheritance of property in class societies [15,23,26].

18 Interestingly, we do not observe the relatively high rates of consanguineous marriage observed in

19 modern-day Central Eurasia in any of the past societies we studied, in Antiquity or earlier. We

20 naturally prefer to remain cautious, especially given the limited sample size of our advanced complex

21 agriculturalist samples from West and Central Eurasia ( $n=21$ and $n=30$, respectively). Nevertheless,

22 it appears possible that modern-day cultural patterns may have emerged late in time, possibly with

23 the spread of Abrahamic traditions in the region. 


\section{References}

1. Mathieson, I., Lazaridis, I., Rohland, N., Mallick, S., Patterson, N., Roodenberg, S.A., Harney, E., Stewardson, K., Fernandes, D., Novak, M., et al. (2015). Genome-wide patterns of selection in 230 ancient Eurasians. Nature 528, 499-503.

2. Ceballos, F.C., Hazelhurst, S., and Ramsay, M. (2018). Assessing runs of Homozygosity: A comparison of SNP Array and whole genome sequence low coverage data. BMC Genomics 19, 106.

3. Cassidy, L.M., Maoldúin, R.Ó., Kador, T., Lynch, A., Jones, C., Woodman, P.C., Murphy, E., Ramsey, G., Dowd, M., Noonan, A., et al. (2020). A dynastic elite in monumental Neolithic society. Nature 582, 384-388.

4. Yengo, L., Wray, N.R., and Visscher, P.M. (2019). Extreme inbreeding in a European ancestry sample from the contemporary UK population. Nat. Commun. 10.

5. McQuillan, R., Leutenegger, A.L., Abdel-Rahman, R., Franklin, C.S., Pericic, M., Barac-Lauc, L., Smolej-Narancic, N., Janicijevic, B., Polasek, O., Tenesa, A., et al. (2008). Runs of Homozygosity in European Populations. Am. J. Hum. Genet. 83, 359-372.

6. Kirin, M., McQuillan, R., Franklin, C.S., Campbell, H., Mckeigue, P.M., and Wilson, J.F. (2010). Genomic runs of homozygosity record population history and consanguinity. PLoS One 5, e13996.

7. Ceballos, F.C., Joshi, P.K., Clark, D.W., Ramsay, M., and Wilson, J.F. (2018). Runs of homozygosity: Windows into population history and trait architecture. Nat. Rev. Genet. 19, 220-234.

8. Kang, J.T.L., Goldberg, A., Edge, M.D., Behar, D.M., and Rosenberg, N.A. (2017). Consanguinity Rates Predict Long Runs of Homozygosity in Jewish Populations. Hum. Hered. 82, 87-102.

9. Jalkh, N., Sahbatou, M., Chouery, E., Megarbane, A., Leutenegger, A.L., and Serre, J.L. (2015). Genome-wide inbreeding estimation within Lebanese communities using SNP arrays. Eur. J. Hum. Genet. 23, 1364-1369.

10. Prüfer, K., Racimo, F., Patterson, N., Jay, F., Sankararaman, S., Sawyer, S., Heinze, A., Renaud, G., Sudmant, P.H., De Filippo, C., et al. (2014). The complete genome sequence of a 
Neanderthal from the Altai Mountains. Nature 505, 43-49.

11. Jones, E.R., Gonzalez-Fortes, G., Connell, S., Siska, V., Eriksson, A., Martiniano, R., McLaughlin, R.L., Gallego Llorente, M., Cassidy, L.M., Gamba, C., et al. (2015). Upper Palaeolithic genomes reveal deep roots of modern Eurasians. Nat. Commun. 6, 8912.

12. Sikora, M., Seguin-Orlando, A., Sousa, V.C., Albrechtsen, A., Korneliussen, T., Ko, A., Rasmussen, S., Dupanloup, I., Nigst, P.R., Bosch, M.D., et al. (2017). Ancient genomes show social and reproductive behavior of early Upper Paleolithic foragers. Science 358, 659-662.

13. Palkopoulou, E., Mallick, S., Skoglund, P., Enk, J., Rohland, N., Li, H., Omrak, A., Vartanyan, S., Poinar, H., Götherström, A., et al. (2015). Complete genomes reveal signatures of demographic and genetic declines in the woolly mammoth. Curr. Biol. 25, 1395-1400.

14. Szpiech, Z.A., Mak, A.C.Y., White, M.J., Hu, D., Eng, C., Burchard, E.G., and Hernandez, R.D. (2019). Ancestry-Dependent Enrichment of Deleterious Homozygotes in Runs of Homozygosity. Am. J. Hum. Genet. 105, 747-762.

15. Walker, R.S. (2014). Amazonian horticulturalists live in larger, more related groups than hunter-gatherers. Evol. Hum. Behav. 35, 384-388.

16. Hill, K.R., Walker, R.S., Božičević, M., Eder, J., Headland, T., Hewlett, B., Hurtado, A.M., Marlowe, F., Wiessner, P., and Wood, B. (2011). Co-residence patterns in hunter-gatherer societies show unique human social structure. Science 331, 1286-1289.

17. Walker, R.S., Hill, K.R., Flinn, M. V., and Ellsworth, R.M. (2011). Evolutionary History of Hunter-Gatherer Marriage Practices. PLoS One 6, e19066.

18. Bowles, S. (2006). Group competition, reproductive leveling, and the evolution of human altruism. Science 314, 1569-1572.

19. Langergraber, K., Schubert, G., Rowney, C., Wrangham, R., Zommers, Z., and Vigilant, L. (2011). Genetic differentiation and the evolution of cooperation in chimpanzees and humans. Proc. R. Soc. B Biol. Sci. 278, 2546-2552.

20. Broushaki, F., Thomas, M.G., Link, V., López, S., van Dorp, L., Kirsanow, K., Hofmanová, Z., Diekmann, Y., Cassidy, L.M., Díez-del-Molino, D., et al. (2016). Early Neolithic genomes from the eastern Fertile Crescent. Science 353, 499-503. 
1 21. Ringbauer, H., Steinrücken, M., Fehren-Schmitz, L., and Reich, D. (2020). Increased rate of close-kin unions in the central Andes in the half millennium before European contact. Curr. Biol. 30, 980-981.

4 22. Scott, E.M., Halees, A., Itan, Y., Spencer, E.G., He, Y., Azab, M.A., Gabriel, S.B., Belkadi, A., Boisson, B., Abel, L., et al. (2016). Characterization of greater middle eastern genetic variation for enhanced disease gene discovery. Nat. Genet. 48, 1071-1079.

7 23. Bittles, A.H., and Black, M.L. (2010). Consanguinity, human evolution, and complex diseases. Proc. Natl. Acad. Sci. U. S. A. 107, 1779-1786.

9 24. Ceballos, F.C., and Álvarez, G. (2013). Royal dynasties as human inbreeding laboratories: The Habsburgs. Heredity (Edinb). 111, 114-121.

11 25. Álvarez, G., Ceballos, F.C., and Berra, T.M. (2015). Darwin was right: inbreeding depression on male fertility in the Darwin family. Biol. J. Linn. Soc. 114, 474-483.

13 26. Korotayev, A. (2000). Parallel-cousin (FBD) marriage, Islamization, and Arabization.

$14 \quad$ Ethnology 39, 395-407.

15 27. Ceballos, F.C., Hazelhurst, S., and Ramsay, M. (2019). Runs of homozygosity in sub-Saharan African populations provide insights into complex demographic histories. Hum. Genet. 138,

28. Sudmant, P.H., Rausch, T., Gardner, E.J., Handsaker, R.E., Abyzov, A., Huddleston, J., Zhang, Y., Ye, K., Jun, G., Fritz, M.H.Y., et al. (2015). An integrated map of structural variation in 2,504 human genomes. Nature 526, 75-81. 


\section{Acknowledgements}

2 We are grateful to the METU CompEvo group and Torsten Günther for helpful suggestions and/or

3 comments, Harald Ringbauer for sharing unpublished results and discussion, Jim Wilson and David

4 Clark for support, and all archaeogenomic groups who have shared their data used in this work. This

5 work was supported by the ERC Consolidator grant “NEOGENE” (Project No 772390 to M.S.).

\section{Author contributions}

7 (a) F.C. and M.S. conceived and designed the study; (b) F.C., K.G., and K.B.V. analysed genetic data, 8 with contributions from D.K. and M.S.; (c) H.C.G, C.K, and Ç.A. determined the historical categories 9 with contributions by Y.S.E.; (d) M.S. supervised the study with contributions by N.E.A., Ç.A., E.S., 10 Y.S.E., A.Gö., F.Ö.; (e) F.C., K.G., M.S. and N.E.A. wrote the manuscript with contributions from all 11 authors. 
1 Table 1. Summary statistics for the genomic inbreeding coefficient calculated from ROH $\left(F_{R O H}\right)$

2 across historical categories and geographical regions.

$3 \mathrm{~N}$ : number of individuals. IQC: interquartile range. $\mathrm{F}>0.0117$ : Individuals with $F_{R O H}>0.0117$

4 (individuals who could be offspring of second cousin matings or closer matings). $\mathrm{F}>0.039$ : Individuals

5 with $F_{R O H}>0.039$ (individuals who could be offspring of first cousin matings or closer matings,

6 ignoring drift). $\mathrm{F}>0.093$ : Number and percentage of individuals with $F_{R O H}>0.093$ (individuals who

7 could be offspring of avuncular matings or closer matings, ignoring drift).

\begin{tabular}{|c|c|c|c|c|c|c|c|c|c|}
\hline & \multirow[t]{2}{*}{$\mathbf{N}$} & \multirow{2}{*}{$\begin{array}{l}\text { Median } \\
\mathbf{F}_{\text {ROH }}\end{array}$} & \multirow[t]{2}{*}{ IQC } & \multicolumn{2}{|c|}{ F $>0.0117$} & \multicolumn{2}{|c|}{$F>0.0391$} & \multicolumn{2}{|c|}{$F>0.0932$} \\
\hline & & & & $\mathbf{N}$ & $\%$ & $\mathbf{N}$ & $\%$ & $\mathbf{N}$ & $\%$ \\
\hline Hunter-Gatherers & 45 & 0.0681 & 0.026 & 45 & 100 & 42 & 93.3 & 5 & 11.1 \\
\hline West Eurasia & 43 & 0.0687 & 0.026 & 43 & 100 & 41 & 95.3 & 5 & 11.6 \\
\hline Central Eurasia & 2 & 0.0397 & 0.006 & 2 & 100 & 1 & 50.0 & 0 & 0.0 \\
\hline Simple Agriculturalists & 107 & 0.0287 & 0.015 & 100 & 93.5 & 18 & 16.8 & 3 & 2.8 \\
\hline West Eurasia & 88 & 0.0291 & 0.015 & 82 & 93.2 & 14 & 15.9 & 3 & 3.4 \\
\hline Central Eurasia & 19 & 0.0201 & 0.017 & 18 & 94.7 & 4 & 21.1 & 0 & 0.0 \\
\hline $\begin{array}{l}\text { Early Complex } \\
\text { Agriculturalists }\end{array}$ & 237 & 0.0251 & 0.012 & 227 & 95.8 & 16 & 6.8 & 1 & 0.4 \\
\hline West Eurasia & 151 & 0.0245 & 0.011 & 143 & 94.7 & 8 & 5.3 & 0 & 0.0 \\
\hline Central Eurasia & 86 & 0.0267 & 0.012 & 84 & 97.7 & 8 & 9.3 & 1 & 1.2 \\
\hline $\begin{array}{l}\text { Advanced Complex } \\
\text { Agriculturalists }\end{array}$ & 51 & 0.0136 & 0.014 & 31 & 60.8 & 2 & 3.9 & 0 & 0.0 \\
\hline West Eurasia & 21 & 0.0012 & 0.021 & 8 & 38.1 & 1 & 4.8 & 0 & 0.0 \\
\hline Central Eurasia & 30 & 0.0151 & 0.006 & 23 & 76.7 & 1 & 3.3 & 0 & 0.0 \\
\hline
\end{tabular}


bioRxiv preprint doi: https://doi.org/10.1101/2020.09.24.311597; this version posted September 24, 2020. The copyright holder for this preprint (which was not certified by peer review) is the author/funder, who has granted bioRxiv a license to display the preprint in perpetuity. It is made available under aCC-BY-NC-ND 4.0 International license.

\begin{tabular}{lccccccccc}
$\begin{array}{l}\text { Human Genome Diversity } \\
\text { Panel }\end{array}$ & 448 & 0.0066 & 0.022 & 172 & 38.4 & 74 & 16.5 & 6 & 1.3 \\
West Eurasia & 139 & 0.0039 & 0.005 & 19 & 13.7 & 3 & 2.2 & 0 & 0.0 \\
Central Eurasia & 309 & 0.0156 & 0.034 & 153 & 49.5 & 71 & 23.0 & 6 & 1.9 \\
\hline
\end{tabular}

1

2 


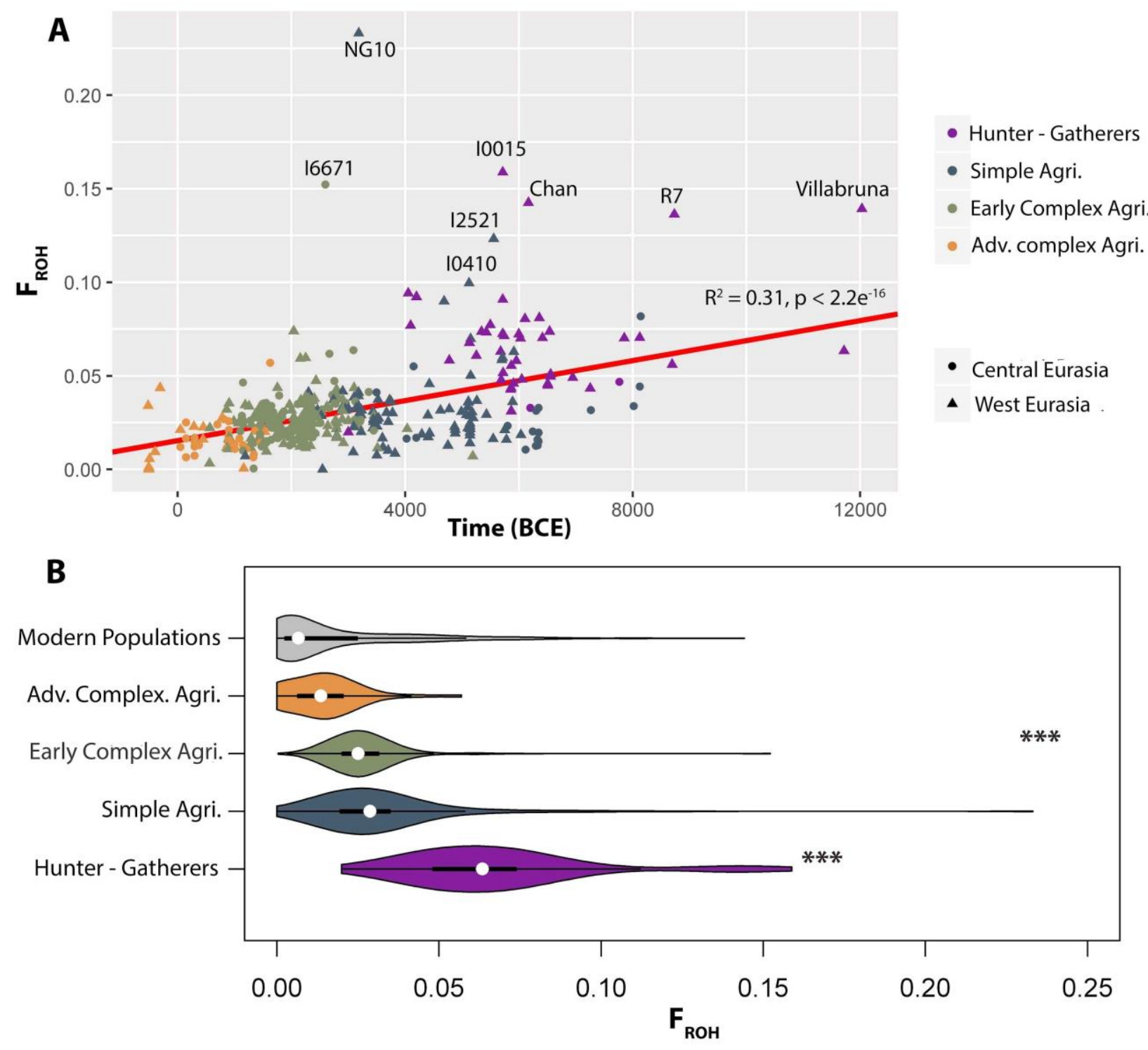

Figure 1. Temporal distribution of the genomic inbreeding coefficient $\left(\mathrm{F}_{\mathrm{ROH}}\right)$.

(A) Regression of $\mathrm{F}_{R O H}$ estimates against time in years Before the Common Era (BCE). Historical categories are defined with colours: Hunter-gatherers in violet, simple agriculturalists (Simple Agri.) in blue, early complex agriculturalists (Early Complex Agri.) in green, advanced complex agriculturalists (Adv. Complex Agri.) in orange, present-day populations from the Human Genome Diversity Panel in grey. Region of origin of each individual is shown with a symbol: Central Eurasia with a circle and West Eurasia with a triangle. The regression line was obtained by analysing only the ancient individuals $(\mathrm{n}=440)$ and has a significant slope $\left(\beta_{\text {Time }}=6.09 \mathrm{e}^{-6}, p=2 \mathrm{e}^{-16}, R^{2}=0.31, p<2.2 \mathrm{e}^{-}\right.$ 16).

(B) Violin plots of $\mathrm{F}_{\mathrm{ROH}}$ estimates for the different historical categories and present-day populations from the Human Genome diversity Panel. Asterisks represent significance $(<0.001)$ calculated by the pairwise Wilcoxon rank sum test with continuity correction. We detected a significant difference between hunter-gatherers and the rest of the groups, and between early complex agriculturalists and advanced complex agriculturalists or HGDP's modern-day populations. 

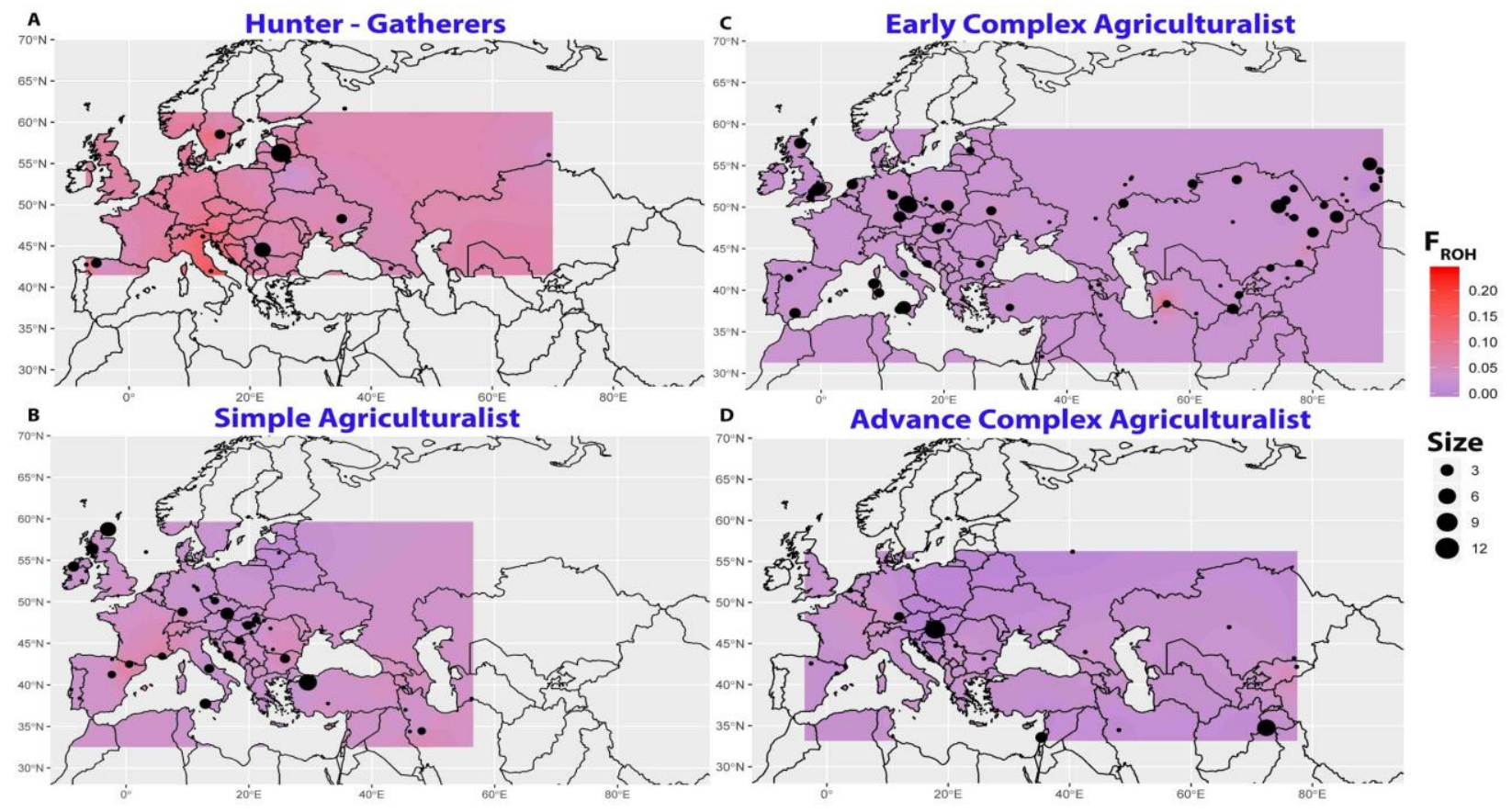

D Advance Complex Agriculturalist

Figure 2. Spatially kriged reconstructions for the distribution of the genomic inbreeding coefficient $\left(\mathrm{F}_{\text {ROH }}\right)$.

5 The colors represent the predicted $\mathrm{F}_{R O H}$ values. The panels show spatial kriging of $\mathrm{F}_{R O H}$ estimates in

6 hunter-gatherers (A), in the simple agriculturalists (B), in the early complex agriculturalists (C), and

7 in the advanced complex agriculturalists (D). 
$\mathbf{A}_{20}$

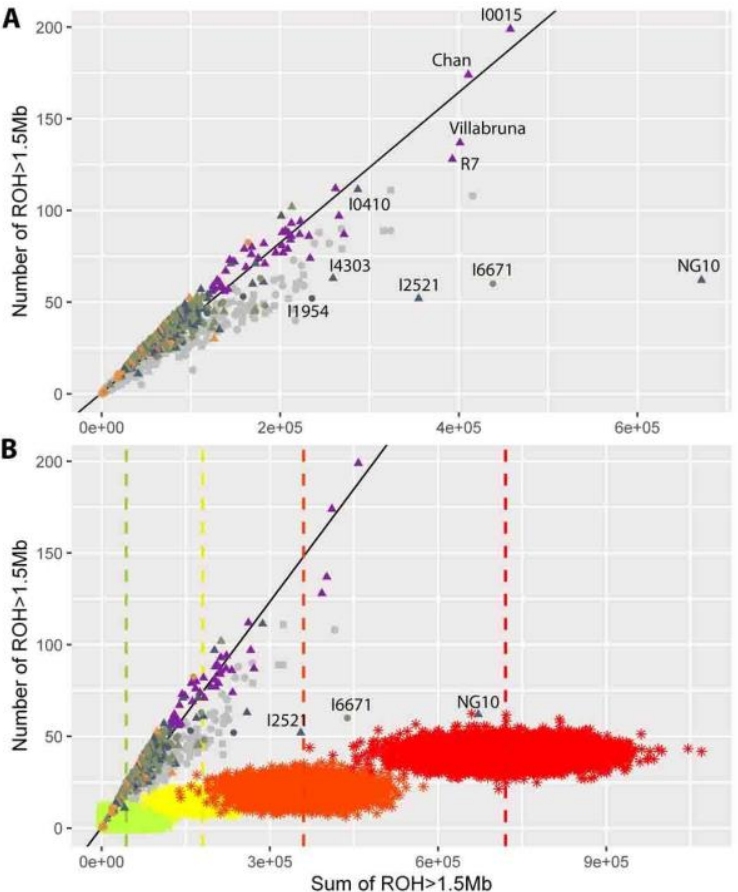

Hunter - Gatherers

- Simple Agri.

- Early Complex Agri.

- Adv. Complex Agri.

- Modern Populations

- Central Eurasia

- West Eurasia

Hunter-Gatherers

- Simple Agri.

- Early Complex Agri.

- Adv. Complex Agri.

Modern Populations

- Central Eurasia

^ West Eurasia
C

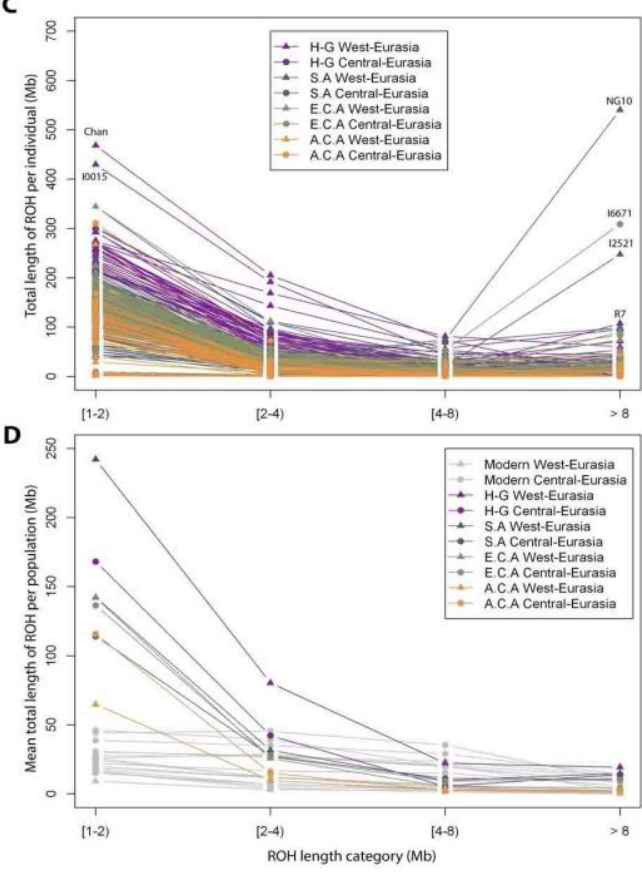

Figure 3. Assessing ROH origins.

3 (A) Mean number of $\mathrm{ROH}$ and sum of $\mathrm{ROH}$, for $\mathrm{ROH}>1.5 \mathrm{Mb}$, is plotted for each individual. The diagonal line is obtained by the regression of the number of ROH vs. the sum of ROH in ASW and ACB populations from the 1000 Genomes Project that represent admixed and thus outbred populations $[27,28]$. Consanguinity practices in the previous generation are visible as a right shift in this figure. (B) Simulations of the number and sum of $\mathrm{ROH}$, for $\mathrm{ROH}>1.5 \mathrm{Mb}$, calculated for the offspring of different consanguineous mating are shown, along with the ancient and modern samples. Asterisks points with different colours designate offspring of different consanguineous mating: second cousin (green), first cousin (yellow) avuncular (orange), incest (red). 5K simulations are represented for each consanguineous mating (see Materials and Methods). Vertical lines represent the average sum of ROH (> 1.5Mb) for the offspring of each type of consanguineous mating. (C) The total length of $\mathrm{ROH}(\mathrm{Mb})$ over four classes of $\mathrm{ROH}$ tract lengths: $1<\mathrm{ROH}<2 \mathrm{Mb}, 2<\mathrm{ROH}<4 \mathrm{Mb}, 4<\mathrm{ROH}<8 \mathrm{Mb}$ and $\mathrm{ROH}>8 \mathrm{Mb}$, described for each ancient individual. Individuals were colored according to region and period: West Eurasia hunter-gatherers (H-G West-Eurasia, shown in purple triangles), Central Eurasian hunter-gatherers (H-G Central-Eurasia shown in purple circles), West Eurasia simple agriculturalist (S.A West-Eurasia shown in blue triangles), Central Eurasian simple agriculturalist (S.A Central-Eurasia shown in blue circles), West Eurasia early complex agriculturalist (E.C.A WestEurasia shown in green triangles), Central Eurasian early complex agriculturalist (E.C.A CentralEurasia green circles), West Eurasia advanced complex agriculturalist (A.C.A West-Eurasia yellow triangles), Central Eurasian advanced complex agriculturalist (A.C.A Central-Eurasia yellow circles). (D) The total length of ROH (Mb) over four classes of ROH tract lengths as in panel C, calculated as the average for the different groups of individuals. The coloring scheme is the same as in panel C; in addition, modern-day populations are represented in grey triangles (Modern West-Eurasian populations) and circles (Modern Central-Eurasian populations). 